\title{
BEARING WITNESS, JORNALISMO EM FLASH E FORMATOS DA LINGUAGEM JORNALÍSTICA DIGITAL ${ }^{1}$
}

\author{
Raquel Longhi ${ }^{2}$
}

\begin{abstract}
Resumo: Bearing Witness é um dos muitos exemplos de formatos jornalísticos produzidos no software Flash para a informação nos meios digitais. Neste artigo, verificamos esta grande reportagem realizada pela Reuters a partir das características próprias de sua linguagem, analisando especialmente o caráter de convergência e combinação de linguagens propiciados pelo meio. Recorremos, para isso, ao trabalho de Mindy McAdams sobre a ideia de Jornalismo em Flash (Flash Journalism), ao aporte semiótico de Júlio Plaza, Tradução Intersemiótica e aos estudos de Arlindo Machado sobre convergência de meios.
\end{abstract}

Palavras-chave: Jornalismo em Flash. Formatos jornalísticos digitais. Convergência de linguagens. Intermídia.

\begin{abstract}
Bearing Witness is one of many instances of journalistic formats produced in the software Flash to the information in the digital media. It was verified in this article this great story covered by Reuters from the own characteristics of its language, analysing especially the character of convergence and combination of languages provided by the media. For that, the work from Mindy McAdams about the idea of Flash Journalism was utilized, within the semiotic support of Júlio Plaza, Tradução Intersemiótica and the studies from Arlindo Machado about the media convergence.
\end{abstract}

Key-words: Flash journalism. Digital journalistic formats. Convergence of languages. Intermedia.

\section{Formatos específicos digitais}

A primeira imagem é a de um soldado em meio a um grande a alto capinzal. Ele olha para um lugar que nós não vemos. O "zoom" vai se fechando, e entra, à direita, um texto acompanhado do título: Bearing Witness. Assim é introduzido o especial da agência de notícias Reuters sobre a atuação de seus cerca de 100 correspondentes durante os cinco

\footnotetext{
${ }^{1}$ Artigo desenvolvido a partir do trabalho Bearing Witness - estudo de um formato específico da linguagem jornalística digital, apresentado no Grupo de Trabalho Estudios sobre Periodismo, no IX Congresso da Alaic, 2008.

${ }^{2}$ Doutora em Comunicação e Semiótica (PUC/SP); professora no Curso de Jornalismo da UFSC, onde também atua na Pós-Graduação em Jornalismo. Membro da Rede de Pesquisa Aplicada Jornalismo e Tecnologias Digitais da SBPJor.
} 
primeiros anos da Guerra do Iraque ${ }^{3}$. Essa grande reportagem multimídia foi publicada em março de 2008, e é um dos exemplos mais contundentes de produtos noticiosos no jornalismo online. Se levarmos em conta não apenas essa, mas diversas outras manifestações no formato hipermídidático que se utiliza do software Flash, veremos que estamos testemunhando um momento importante para o jornalismo, que sinaliza para um avanço dos formatos específicos de linguagem no meio digital.

Muitos estudos têm se debruçado sobre a construção da informação nos meios digitais, a maioria deles creditando aos avanços tecnológicos um dos fatores essenciais nessa evolução. Analisando a função das redações, Boczkowski (2006), por exemplo, conclui que as práticas relacionadas com a tecnologia são fundamentais para o trabalho editorial que implica a construção de conteúdo informativo nos jornais online (Boczkowski, 2006). No que diz respeito especificamente à construção de conteúdos, uma das tendências mais interessantes está na ideia de Flash Journalism, desenvolvida por Mindy McAdams. A expressão designa aqueles produtos informativos elaborados para o meio digital que se utilizam do software $\mathrm{Flash}^{4}$ para sua concepção. Seus primeiros formatos eram "pacotes online", segundo a autora, compostos por slideshows contendo fotografias acompanhadas de som. Por volta de 2001, essas foram as primeiras manifestações de que algo estava acontecendo com a linguagem jornalística nos meios digitais, que ia além do hipertexto.

Uma forma diferente de apresentar o fotojornalismo, o slideshow liderou esse tipo de conteúdo no ciberjornalismo até que o Flash e outras possibilidades técnicas foram adquirindo predominância para a feitura da notícia nos meios digitais. O ano era 2005, e, mais uma vez, a linguagem do jornalismo digital dava um passo além: especiais em hipermídia começam a tomar cada vez mais espaço nos sítios jornalísticos, mostrando que a convergência de linguagens é o principal sujeito das transformações.

Bearing Witness é um dos incontáveis exemplos de formatos jornalísticos produzidos em Flash para a informação nos meios digitais. Neste artigo, verificamos esse especial multirmídia a partir das características próprias da linguagem digital, analisando seu desenho e levando em conta o caráter de convergência e combinação de linguagens propiciados pelo meio, concebido como intermídia (Longhi, 2008). Como suporte teórico, utilizamos os

\footnotetext{
3 "Bearing Witness, Five Years of the Iraq War", disponível em: http://iraq.reuters.com/. Acesso em 20/04/2008.

${ }^{4}$ Software criado em 1992, atualmente propriedade da Macromedia.
} 
conceitos de "tradução intersemiótica", de Júlio Plaza (2001) e de convergência de meios, por Arlindo Machado (2007).

\section{Desenho e interface}

Combinando slideshow com documentário, Bearing Witness ${ }^{5}$ recebe um tratamento cinemático da linguagem, ao mesmo tempo em que integra infográficos. Além de remodelar linguagens, o especial também incorpora estratégias narrativas, formatos ou gêneros, atestados, por exemplo, quando joga com as características da edição em ritmo acelerado consagrada pelo videoclipe, como se verá mais adiante. Premiado com o New York Photo Awards Multimedia Winner, o especial explora o conteúdo fotográfico até o limite, aproveitando as possibilidades da "linha do tempo", proporcionada pelo software, em que as imagens são mostradas lado a lado, e ativadas pela passagem do mouse, ou como slides, sempre acompanhadas de textos informativos. Tais manifestações mostram linguagens recombinantes, que se fundem num ambiente caracterizado pela fluidez da informação. Como se dá, porém, a concepção de desenho relativa à interface do meio nesse tipo de produto?

O desenho da informação jornalística vem ganhando maior interesse, nos meios digitais, exatamente pela utilização de recursos técnicos. Assim como no impresso, o princípio fundamental da associação indissolúvel entre conteúdo e forma também define a configuração da informação no digital. Sabe-se que a função da interface, nesse contexto, tem sido elemento fundamental, já que, como afirma Manovich (2006), "em termos semióticos, a interface de computador atua como um código que transporta mensagens culturais em uma diversidade de suportes" (Manovich, 2006: 113). Assim como em grande parte dos chamados "especiais jornalísticos" produzidos em Flash, a interface torna-se o espaço privilegiado de "leitura", pois engloba todos os elementos informativos que darão origem às diversas partes do produto informativo. Nossa análise, nesse sentido, começa pela abertura, que apresenta um breve texto introdutório, ladeado por uma foto em tamanho maior que a metade da tela e ligações para as "seções", divididas em Introdução, Perfis, Linha do tempo, Mapas e Fontes, como se pode ver na Figura 1.

\footnotetext{
${ }^{5}$ Em tradução nossa, com o uso do Dicionário Oxford: “Apresentando provas”.
} 


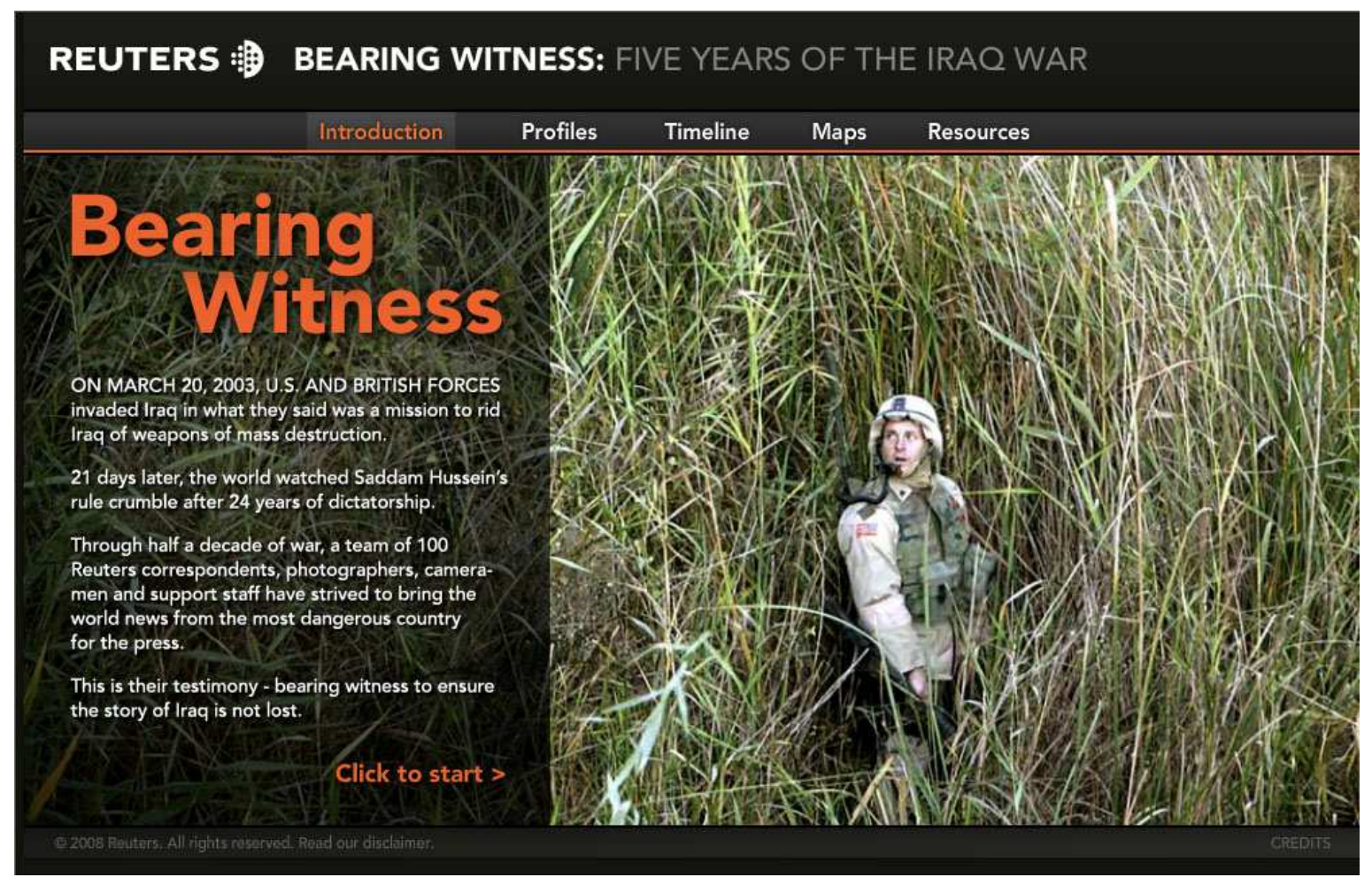

Fig. 1. Abertura do especial da Reuters sobre os cinco anos da Guerra do Iraque (Fonte: http://iraq.reuters.com - acesso em 31/03/2008).

O esquema a seguir representa a estrutura básica de ligações entre as partes desse produto, que podem ser entendidas, ainda, como "camadas" que se interpõem e dialogam entre si. (Figura 2): 


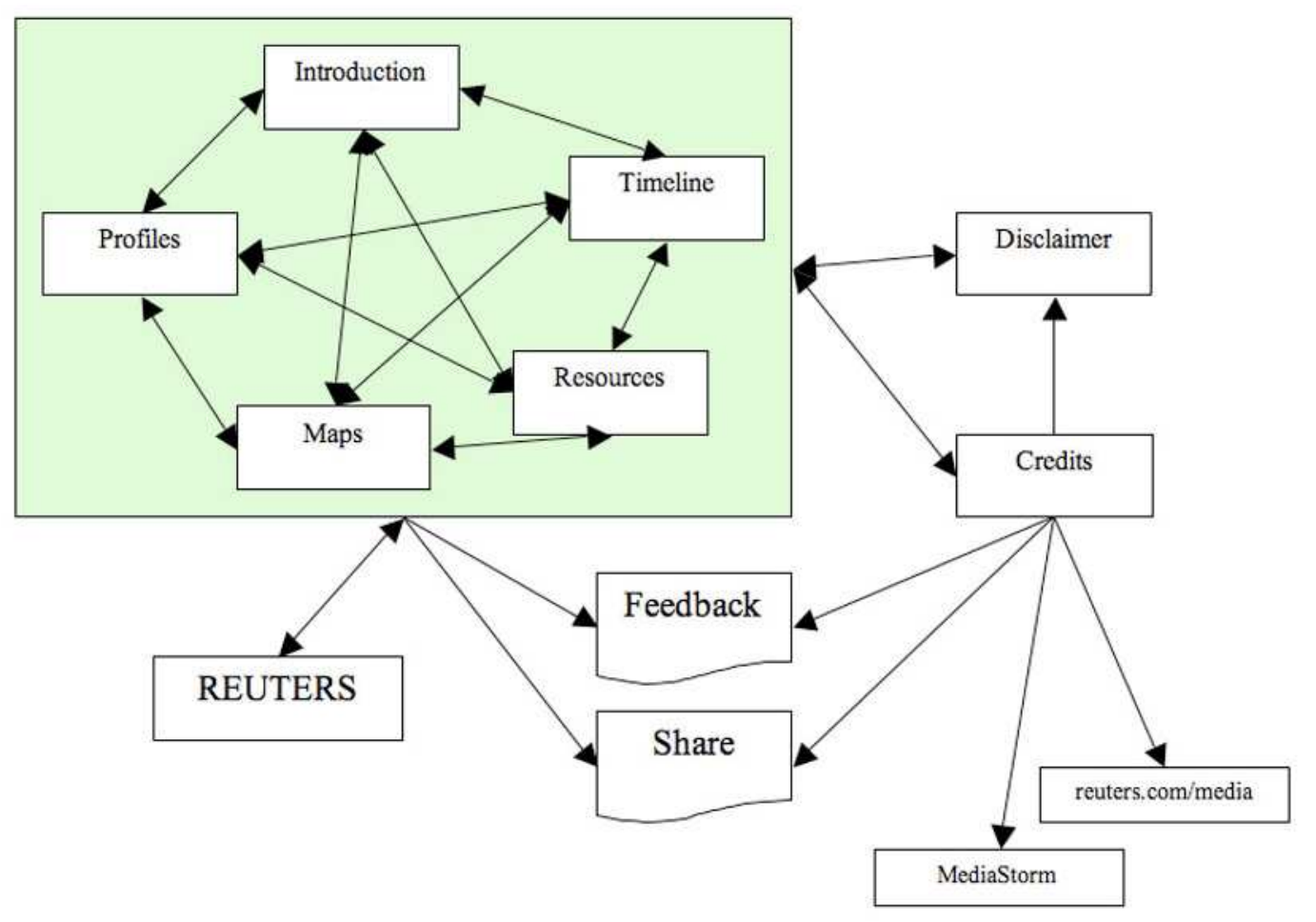

Fig. 2. Mapa simplificado das relações entre as várias lexias de Bearing Witness. (Fonte: TORRES, 2008).

Estruturados em forma de estrela, segundo a análise de Torres (2008), o que permite uma grande navegabilidade, cinco pontos principais marcam a interface introdutória de Bearing Witness:

A exploração começa na lexia Introduction, de onde se pode prosseguir assistindo ao vídeo introdutório ou simplesmente pular para qualquer outra lexia de maior interesse. De qualquer uma das cinco páginas, podemos acessar qualquer outra: não há hierarquia. Dentro das páginas Maps e Profiles a estrutura não hierárquica repete-se, respectivamente, nos mapas temáticos e nos três jornalistas-personagens. Completando o site, links para a home page da Reuters, e-mail, Créditos e Disclaimer são acessíveis de todas as páginas de conteúdo. A fusão conceitual de mídias (...) permeia o produto: fotografia, vídeo, áudio, texto e design gráfico cruzam-se de maneira transparente, possibilitando uma linguagem intermídia. (TORRES, 2008: $\left.\mathrm{s} / \mathrm{n}^{\mathrm{o}}\right)$.

Numa rápida descrição, já que mais adiante faremos uma análise mais detalhada, podemos apresentar as diversas partes (ou lexias) de Bearing Witness conforme segue: 
A opção Introdução (Introduction) comenta a Guerra através da fala de Andrew Marshall, chefe da unidade da Reuters no Iraque de 2003 a 2005, em imagens que mesclam o entrevistado com vídeos e fotos do conflito e da ação dos repórteres e jornalistas, em quase cinco minutos. Na lexia Perfis (Profiles), três profissionais fazem o testemunho do conflito; a primeira, Samia Nakhoul, jornalista chefe do birô da Reuters no Golfo, cobrindo o Iraque desde 1991. O segundo, o fotógrafo Goran Tomasevic, cobrindo a guerra desde 2002, e o terceiro, o atual chefe do birô em Bagdá, Dean Yates, desde 2003. Na seção Linha do tempo (Timeline), imagens fotográficas combinam-se com recursos de movimento para situar historicamente o conflito. Já em Mapas (Maps), aparecem infográficos distribuídos por assuntos, como População, Petróleo, etc. A opção Recursos (Resources) mostra fontes e materiais produzidos sobre os cinco anos do conflito.

O desenho da interface, no jornalismo em Flash, vai ganhar, ainda, com a convergência de linguagens, como veremos a seguir.

\section{Jornalismo em Flash}

Numa primeira fase de desenvolvimento do meio, as informações no jornalismo online eram construídas através da ligação entre páginas da $W W W$, conforme as possibilidades do hipertexto, o que era mais comum, conforme McAdams (2005: 10). O surgimento do software Flash, apesar de não ser determinante para o novo formato da notícia num primeiro momento, teve enorme influência sobre o mesmo na criação de pacotes de informação, conforme a mesma autora. "Em alguns casos, observa ela, um pacote é um arquivo de histórias sobre um mesmo tema. Em outros, uma única história com vários elementos ligados, como vídeo, slideshows e um mapa" (McAdams, 2005: 10). Tais elementos poderiam ter aparecido, primeiramente, em outro meio, ou ser criados especificamente para o uso online. Esses produtos, porém, ganharam em agilidade com o programa, principalmente pela habilidade na combinação dos mesmos.

Não é de se estranhar que McAdams considere os produtos jornalísticos em Flash como os formatos jornalísticos por excelência dos meios digitais. Para ela, o aplicativo e o tipo de jornalismo que produz não podem ser separados neste momento (McAdams, 2005: 23). Isso resulta da capacidade do Flash de produzir aplicações jornalísticas que se utilizam de vários formatos de linguagem, em janelas únicas, e ainda, com animações complexas em arquivos bastante reduzidos. Além disso, esse software, mistura de ferramenta de autoria com 
meio de disponibilização de conteúdo, funciona como um tocador de mídia no qual arquivos de vídeo, foto ou sons são disponibilizados sem necessitar de plug-ins específicos. Ou seja, o Flash compõe-se não somente da própria ferramenta de produção, mas também do tocador (player) e do plug-in. Esses dois últimos estão disponíveis para download na rede a qualquer usuário. No que diz respeito ao desenho da informação, o aplicativo é um modo fácil de controlar a apresentação final do produto, segundo o desenvolvedor Jacek Arymiak, entrevistado pela mesma autora: “(o Flash) é o PDF da multimídia interativa”, diz ele (apud McAdams, 2005: 28).

Pela sua característica de reunir numa mesma janela vários formatos de linguagem, esse software torna mais fácil a combinação entre mensagens verbais, sonoras e visuais. "Ao invés de haver janelas separadas para mostrar vídeo, mapas, galerias de fotos ou texto, todos estes elementos podem ser combinados numa interface única e simples" (McAdams, 2005: 30). Desta forma, os elementos podem ser colocados em camadas, capazes de serem acessadas alternadamente, e ainda dialogam entre si nas mesmas coordenadas da tela, sem a necessidade de uma nova página.

O que o Flash faz, na verdade, é dar forma à remodelação de que falam Bolter e Grusin (1999), que seria a principal característica dos novos meios. Podemos verificar tal estratégia a partir de uma breve análise desse especial, que procedemos a seguir.

Formatos como a fotografia aparecem remodelados pelas características do suporte, recebendo maiores recursos expressivos através da edição de imagens, como se percebe na seção Profiles, no testemunho do fotógrafo Goran Tomasevic, quando relembra o episódio da derrubada da estátua de Saddam Hussein. A montagem remete ao universo do videoclipe, quando as fotos são apresentadas em slideshow numa sucessão de capas de jornais impressos e digitais de vários países que retrataram o acontecimento. A estratégia é mostrar o conjunto de imagens utilizando recursos que reforçam a narrativa imagética, tais como a montagem: em um momento, uma edição tradicional, cujo ritmo fica entre os já consagrados pelo documentário em cinema e vídeo. Em outro momento, uma edição frenética, cujos takes não passam de milésimos de segundo, aproximando-se bastante da estética do videoclipe, que instituiu a forma da flicagem, efeito produzido por uma montagem muito rápida, com planos curtos, quase ao nível do quadro-a-quadro, dando a impressão de um "pisca-pisca" bastante acelerado, na definição de Arlindo Machado (1995: 212). 
A aba Timeline apresenta uma linha do tempo na qual uma sucessão de imagens fornece a essência dos acontecimentos. O recurso do mouseover, que permite o movimento das imagens pela manipulação do mouse sobre as mesmas, possibilita que recebam movimento: elas são dispostas lado a lado, podendo ser acessadas uma a uma, quando então aparecem em tamanho aumentado, acompanhadas do respectivo texto informativo. Tal ação é caracterizada pela alternância na sua própria "velocidade", característica propiciada pelo aplicativo, que permite reduzir ou aumentar a aceleração da "passagem" do mouse pela tela, a partir da sua manipulação sobre a interface.

É na aba Maps que vão aparecer os infográficos, divididos em cinco categorias: Overview, Oil, Population, Fatalities e Journalist Safety. Embora nossa análise não esteja dirigida ao conteúdo, é notável verificar de que maneira tal subdivisão engloba os principais temas relativos ao conflito, como o petróleo e a população. Na sua forma, os infográficos apresentados ficam mais para o estilo estático do que, propriamente, para um formato que se tem utilizado em larga medida nos meios digitais: o do infográfico em movimento. Essa opção, se por um lado atesta uma simplificação do recurso, como pode parecer a leitores já habituados ao movimento da infografia no online, por outro mostra que a simplicidade da forma também tem efeitos eficazes no conjunto do conteúdo. No caso de Bearing Witness, trata-se de utilizar um recurso na sua forma mais elementar: o infográfico, aqui, é apenas um infográfico.

\section{Tradução Intersemiótica e Intermídia}

O que hoje parece dominar o pensamento sobre os processos comunicativos, especialmente do ponto de vista da linguagem, tem raízes na trajetória dos estudos sobre Comunicação que remetem a McLuhan, na década de 60, quando esse autor investigava as características dos meios de comunicação, especialmente a partir do advento da televisão e do que, para ele, instaurava a era da eletrônica, que seria seguida pelo computador.

No Brasil, Júlio Plaza elaborou o que definiu como "Tradução Intersemiótica”, em que a linguagem era vista pela passagem intersígnica, na qual o trânsito de signos por diferentes suportes produz novos signos, e assim, linguagens renovadas.

A Tradução Intersemiótica se pauta, (...) pelo uso material dos suportes, cujas qualidades e estruturas são os interpretantes dos signos que absorvem, servindo como interfaces. Sendo assim, o operar tradutor, para nós, é mais 
do que a 'interpretação de signos lingüísticos por outros não-lingüísticos'. Nossa visão diz mais respeito às transmutações intersígnicas do que exclusivamente à passagem de signos lingüísticos para não-lingüísticos (...) (PLAZA, 2001: 67).

O importante para se entender tais operações, desta forma, é ler, "na raiz da aparente diversidade das linguagens e suportes, os movimentos de passagem dos caracteres icônicos, indiciais e simbólicos não apenas nos intercódigos, mas também no intracódigo" (Plaza, 2001: 67). Ou seja, devem ser levados em conta os processos e leis de articulação de linguagem que se efetuam no interior de um suporte ou mensagem. Da mesma idéia partilha Lúcia Santaella (2007), para quem

...processos comunicativos e formas de cultura que nelas se realizam devem pressupor tanto as diferentes linguagens e sistemas sígnicos que se configuram dentro das mídias em consonância com o potencial e limites de cada mídia, quanto deve pressupor também as misturas entre linguagens que se realizam nas mídias híbridas de que o cinema, a televisão e, mito mais, a hipermídia, são exemplares. (SANTAELLA, 2007: 77-78).

Combinação, mesclagem, hibridações, intercâmbios, diálogos, a palavra importa menos do que a noção de convergência. McLuhan, interessado nas então novas configurações da mensagem, advertia para a combinação e reprocessamento de meios, que resultaria num ambiente no qual "o meio é a mensagem" (McLuhan, 1974: 11). Para esse autor, a famosa frase significava que, na era da eletrônica (cuja televisão era o principal suporte) estaria se criando um ambiente totalmente novo, composto pelo conteúdo de ambientes anteriores, mecanizados, da era industrial. "O novo ambiente reprocessa o velho tão radicalmente quanto a TV está reprocessando o cinema. Pois o 'conteúdo' da TV é o cinema” (McLuhan, 1974: 12), dizia o canadense. Para o autor, o híbrido seria um momento de revelação, do qual nasceria a forma nova. Dentro de sua reflexão sobre os novos meios, então, anunciava o potencial tradutor dos computadores: "Hoje, os computadores parecem prometer os meios de se poder traduzir qualquer língua em qualquer outra, qualquer código em outro código - e instantaneamente" (McLuhan, 1974: 98).

Na década de 1980, no Brasil, as primeiras utilizações do computador como meio de comunicação, especialmente com o advento do videotexto, anunciavam o caráter híbrido dos meios digitais, conforme os estudos de Júlio Plaza (2001). Verificando o potencial do computador como meio de combinação de linguagens, esse autor desenvolveu a idéia de 
"transmutações intersígnicas" para dar conta de tais rearranjos e da ausência de demarcação das fronteiras entre os diversos sistemas sígnicos. Assim, segundo Plaza, o verbal, o pictórico, o fotográfico, o fílmico, o televisivo, o gráfico, o musical, etc, são levados em conta numa sua combinação como transdução, que estaria pautando o desenvolvimento dos meios tecnológicos:

O carácter transductor e de interface das novas formas eletrônicas torna-se agora de uma importância ainda não avaliada na sua dimensão exata. De fato, na sociedade tecnológica, a tendência cada vez mais vai no sentido do uso de processos transcodificadores e tradutores de informação entre diferentes linguagens e meios. (...) (PLAZA, 2001: 206).

Mais do que produtos, seriam processos de deslocamento e nova alocação da informação (Plaza, 2001: 206). Da mesma forma, o autor considera que os meios estariam sendo substituídos pela ideia de "passagens": "Não existe mais meio, somente trânsito de informações entre suportes, interfaces, conceitos e modelos como meras matrizes numéricas" (PLAZA, 2001: 75).

Júlio Plaza foi um dos primeiros estudiosos a notar os caminhos da linguagem entre os meios, então, eletrônicos. Ele observou, ainda, tais processos em duas vertentes: o que estava se configurando como multimídia, composto por uma simples colagem de linguagens, e como intermídia, definida como síntese qualitativa da hibridação de meios:

Tanto multimídia como intermídia são categorias interdisciplinares que, como colagem ou síntese-qualitativa, colocam em questão as formas de produção-criação individual e sobretudo a noção de autor. (...) ...os meios tecnológicos absorvem e incorporam os mais diferentes sistemas sígnicos, traduzindo as diferentes linguagens históricas para o novo suporte. Essas linguagens transcodificadas efetivam a colaboração entre os diversos sentidos, possibilitando o trânsito intersemiótico e criativo entre o visual, o verbal, o acústico e o tátil. (PLAZA, 2001: 66).

Trata-se de uma linguagem Zen, conforme o autor, que incorpora as "Três Perfeições" (Poesia - Pintura - Caligrafia). A ideia da quintessência da expressão chinesa na arte é um dos fundamentos para se pensar a fusão conceitual, conforme Longhi (2002). 
A arte chinesa compreendia a cultura de forma holística e para isso buscava harmonizar o culto à caligrafia, à pintura e à poesia. A idéia era que esses eram meios intercambiáveis de expressão e que o artista podia facilmente transpor seu impulso criativo de uma forma à outra. (LONGHI, 2002: 4).

Para a arte chinesa dos séculos VIII, IX, X e XI, a cultura era compreendida de forma holística, e para isso era preciso harmonizar a caligrafia, a pintura e a poesia. A ideia era que esses eram meios intercambiáveis de expressão, e que o artista podia facilmente transpor seu impulso criativo de uma forma a outra, utilizando um único suporte. Como bem referiu Antônio Risério, não se trata da palavra escrita, mas da palavra pintada (Risério, 1998).

A noção de intermídia, para Plaza, está bastante ligada a tais movimentos por diferentes suportes, que hoje aparece na concepção de convergência, como um aspecto que os diferencia de tudo o que vem antes, embora, vistos pela trajetória histórica de sua evolução, seja possível identificar estratégias de combinação de meios e linguagens. O conceito de intermídia pode dar conta da fusão conceitual operada pelas estratégias de remodelação de meios e linguagens que marcam os produtos digitais. Intermídia seria um modo de olhar para tal aglutinação que vai além da simples colocação dos elementos na tela do computador: traduz-se mais pela combinação conceitual, pela mistura de meios que, ao se mesclarem, mantêm algumas características e adquirem outras, produzindo formatos específicos de linguagem. Desta forma, pode-se definir uma narrativa intermídia, que aposta na fusão conceitual de diferentes linguagens em prol de uma linguagem específica. (Longhi, 2008: 5 ).

Para Arlindo Machado (2007), é hora de apostar na ideia de convergência como a melhor alternativa para se pensar os meios no campo da comunicação. Isso porque, no interior de cada meio, há conflito, embate, surgimento de novas tendências e movimentos antagônicos. Levando em conta ser impossível "delimitar com exatidão o campo abrangido por um meio de comunicação ou uma forma de cultura, pois as suas bordas são imprecisas e se confundem com outros campos" (Machado, 2007: 58), esse autor sistematiza, para exemplificar, a música, a fotografia e o cinema em círculos que se tangenciam. Haveria maior zona de interpenetração entre os círculos relacionados à fotografia e ao cinema, e menor destes com a música. Para simbolizar as especificidades de cada meio, porém, o autor propõe outra configuração: de núcleos preenchidos por uma mancha gráfica de densidade variável, significando aquilo que o diferencia de outros meios (Figura 3). 


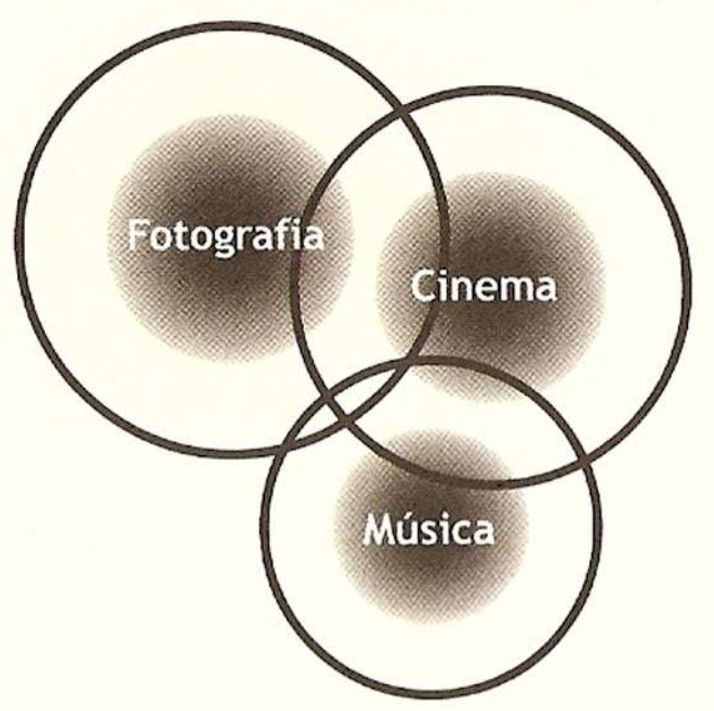

Fig. 3. Representação de meios e suas interseções e tangenciamentos. (Fonte: Machado, 2007: 60)

Para o autor, cada círculo teria o seu "núcleo duro", onde estariam definidos conceitos, práticas, modos de produção, tecnologias, economias e públicos específicos. À medida que se aproxima das bordas, porém, “a diferenciação entre os meios já não é tão evidente, os conceitos que os definem podem ser transportados de uns para outros, as práticas e as tecnologias podem ser compartilhadas, o sustentáculo econômico e o público atingido podem ser os mesmos" (Machado, 2007: 59).

Apesar de uma visível interseção, explicada pelo autor, tal representação ainda é inexata, pois pode dar a impressão de que o mundo da cultura e dos meios é estático, podendo ser demarcado. Ele propõe, então, um outro esquema, no qual acontece uma expansão em progressão geométrica dos repertórios de cada meio (Figura 4), salientando que "chega um momento em que a ampliação dos círculos atinge tal magnitude que há interseção não apenas nas bordas, mas também nos seus "núcleos duros"” (Machado, 2007: 65). 


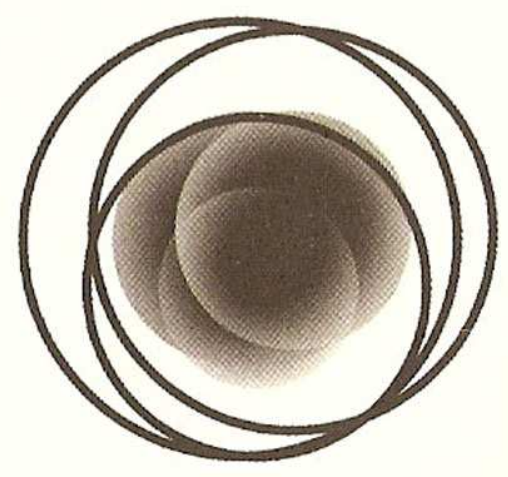

Fig. 4. Interseção nos "núcleos duros” das representações dos meios. (Fonte: Machado, 2007: $65)$.

O momento da convergência dos meios, para esse autor, então, estaria representado na situação acima, ou seja, "quando o centro mais denso do círculo, identificador de sua especificidade, começa a se confundir com os outros" (2007, p. 65). A sistematização de Machado representa bem a concepção de intermídia como fusão conceitual, e colabora no embasamento do estudo doas transformações por que passa a linguagem nos novos meios digitais de comunicação.

\section{Considerações finais}

Um estudo das características da linguagem da notícia no ambiente digital não pode ser separado da verificação a respeito da convergência, já que esta é definidora do atual estado da arte relativa não somente aos formatos jornalísticos, mas a diversas manifestações da comunicação hipermidiática. Por sua vez, a convergência deve ser vista sob dois aspectos, que se relacionam entre si: a combinação de linguagens e a remodelação de meios, através da sua hibridação. Isso porque, o que se entende por "meio" inclui, necessariamente, a instância da linguagem.

A concepção de intermídia vem colaborar para o entendimento das estratégias de convergência, que vão além da simples colagem, para efetivar-se numa fusão que opera conceitualmente, no nível do seu significado. Pode ser examinada, assim, à luz da Tradução Intersemiótica, que verifica as passagens da linguagem nos meios digitais, nas quais o trânsito de signos por diferentes suportes produz novos signos, e assim, linguagens renovadas. 
Neste breve artigo, verificamos os formatos específicos nos meios digitais através do estudo de um produto noticioso, levando em conta seu desenho e a convergência de meios e linguagens. Acompanhando a evolução da informação no jornalismo digital, verificamos a função do desenvolvimento da tecnologia, especialmente de softwares, como definidores para tais avanços. O Flash, assim, tem se configurado como a ferramenta mais importante na construção da linguagem específica do meio, ou seja, adaptada às características oferecidas pela hipermídia. Produtos como Bearing Witness, nesse sentido, são modelos para examinar a evolução da linguagem nos novos meios.

\section{Referências bibliográficas}

BOCZKOWSKI, Pablo J. Digitalizar las noticias. Innovación em los diários online. Buenos Aires: Manantial, 2006.

BOLTER, J. David e GRUSIN, Richard. Remediation. Understanding new media. Cambridge, Massachussets: The MIT Press, 1999.

CAMPOS, Haroldo. Ideograma. lógica, poesia, linguagem. São Paulo: Perspectiva/Edusp, 2000.

CAMPOS, Haroldo, Campos, Augusto e Pignatari, Décio. Teoria da Poesia Concreta - textos críticos e manifestos. 1950-60. 2.ed. São Paulo: Livraria Duas Cidades, 1975.

HIGGINS, Dick (1984). Horizons. The poetics and theory of the Intermedia. Carbondalle and Edwardsville: Southern Illinois University Press.

LIMA Jr., Walter. Infografia multimedia avança na vanguarda do jornalismo mundial. In: V Congresso Iberoamericano de Periodismo en Internet, Salvador, 2004.

LONGHI, Raquel R. Intermedia, ou Para entender as Poéticas Digitais. In: XXV Congresso Brasileiro de Ciências da Comunicação, 2002. Anais. Salvador: Intercom, 2002. Infografia online: narrativa intermídia”. In: 17ª Compós, São Paulo, 2008.

MACHADO, Arlindo. Arte e Mídia. Rio de Janeiro: Jorge Zahar Ed., 2007. A arte doVídeo. São Paulo, Brasiliense, $3^{\mathrm{a}}$. ed., 1995.

McADAMS, Mindy. Flash Journalism. How to create multimedia news packages. Burlington, MA, USA: Focal Press/Elsevier, 2005.

MCLUHAN, Marshall. Os meios de comunicação como extensões do homem (Understanding media). Trad.: Décio Pignatari). São Paulo: Editora Cultrix, 1974.

PLAZA, Júlio. Tradução Intersemiótica. São Paulo: Perspectiva, 2001. 
STEVENS, Jane. What is a Multimedia Story? Disponível em: $<$ http://multimedia.journalism.berkeley.edu/tutorials/reporting/starttofinish/choose/> $\quad$ Acesso em 05/10/2008.

SANTAELLA, Lúcia. As linguagens como antídoto ao midiacentrismo. In: Revista Matrizes. São Paulo: Pós-Graduação em Comunicação da USP, 2007, pág. 75-98.

TORRES, Jessé. Análise da estrutura de Bearing Witness. Florianópolis, UFSC, 2008 (mimeo). 